\title{
Correction to: Assessing the impacts of Amphan cyclone over West Bengal, India: a multi-sensor approach
}

\author{
Rajesh Kumar (1) - Seema Rani • \\ Pyarimohan Maharana
}

Published online: 5 June 2021

(C) Springer Nature Switzerland AG 2021

\section{Correction to: Environ Monit Assess (2021) 193:283 https://doi.org/10.1007/s10661-021-09071-5}

The original version of this article unfortunately contained minor mistakes in the abstract and introduction section.

A line in the Abstract section should be read as 'The present study aims to analyse the impacts of Amphan cyclone on land use/land cover (LULC) such as built-up area, cropland, brick-kiln industries and vegetation cover of nine districts of W.B. namely, Barddhaman, Nadia, North 24 Parganas, South 24 Parganas, Purba Medinipur, Paschim Medinipur, Haora, Hugli and Kolkata' instead

The original article can be found online at https://doi.org/ 10.1007/s10661-021-09071-5.

\section{R. Kumar $(\bowtie)$}

Centre for the Study of Regional Development, Jawaharlal Nehru University, New Delhi, India

e-mail: rajeshcsrd@gmail.com

R. Kumar

Department of Geography, Sikkim University, Gangtok, Sikkim, India

S. Rani

Department of Geography, Institute of Science, Banaras Hindu University, Varanasi, Uttar Pradesh, India

P. Maharana

School of Environmental Sciences, Jawaharlal Nehru University, New Delhi, India

\section{P. Maharana}

Faculty of Science, Sri Sri University, Cuttack, Odisha, India of 'The present study aims to analyse the impacts of Amphan cyclone on land use/land cover (LULC) such as built-up area, cropland, brick-kiln industries and vegetation cover of nine districts of W.B. namely, Barddhaman, Nadia, North 24 Parganas, South 24 Parganas, Purba Medinipur, Paschim Medinipur, Haora, and Kolkata'.

A line in the first paragraph of the Introduction section should be read as 'Frequent tropical cyclones occur over the Bay of Bengal during November and May months (Singh et al., 2000)' instead of 'Frequent tropical cyclones occur over the Bay of Bengal during November-May months (Singh et al., 2000)'.The last line of the Introduction section should be read as 'Considering the level of the severity of the Amphan cyclone, the present study aims to analyse the impacts of the cyclone on LULC (built-up area, cropland, brick-kiln industries and vegetation cover) of nine districts of W.B. namely, Barddhaman, Nadia, North 24 Parganas, South 24 Parganas, Purba Medinipur, Paschim Medinipur, Haora, Hugli and Kolkata' instead of 'Considering the level of the severity of the Amphan cyclone, the present study aims to analyse the impacts of the cyclone on LULC (built-up area, cropland, brick-kiln industries and vegetation cover) of nine districts of W.B. namely, Barddhaman, Nadia, North 24 Parganas, South 24 Parganas, Purba Medinipur, Paschim Medinipur, Haora and Kolkata'.

Publisher's Note Springer Nature remains neutral with regard to jurisdictional claims in published maps and institutional affiliations. 